\title{
Limitations of the DiaRem Score in Predicting Remission of Diabetes Following Roux-En-Y Gastric Bypass (RYGB) in an ethnically Diverse Population from a Single Institution in the UK
}

\author{
George Tharakan $^{1,2}$ - Rebecca Scott ${ }^{1,2}$. Olivia Szepietowski ${ }^{1,4}$ - Alexander D. Miras ${ }^{1,2}$. \\ Alexandra I. Blakemore ${ }^{1,4} \cdot$ Sanjay Purkayastha $^{3} \cdot$ Ahmed Ahmed $^{3}$. \\ Harvinder Chahal $^{1,2}$ - Tricia Tan ${ }^{1,2}$
}

Published online: 10 September 2016

(C) The Author(s) 2016. This article is published with open access at Springerlink.com

\begin{abstract}
Purpose This study aimed to determine the predictive power of the DiaRem score following Roux-en-Y gastric bypass to identify patients who would have diabetes remission at 1 year in an ethnically diverse population.

Methods We performed a retrospective review of 262 patients with type 2 diabetes mellitus who underwent RYGB at the Imperial Weight Centre, UK, from 2007 to 2014. Data was collected on the parameters required to calculate the DiaRem score as well as pre- and post-surgical weight and the ethnicity of the subjects.

Results The studied cohort was ethnically diverse $(61.3 \%$ Caucasian, $10.3 \%$ Asian, $5.3 \%$ black, $2.6 \%$ mixed and $20.6 \%$ other). At 1-year post-surgery, there were significant reductions in mean weight (133.4 to $94.3 \mathrm{~kg}$ ) and BMI (46.7 to $33.3 \mathrm{~kg} / \mathrm{m}^{2}$ ). The mean HbAlc decreased from 8.2 to $6.1 \%$, and $32.5 \%$ of the cohort underwent either partial or complete remission. $67.8 \%$ of the patients that were classified in group 1 of the DiaRem score (most likely to have remission) had

Tricia Tan

t.tan@imperial.ac.uk

1 Department of Medicine, Imperial College London, London, UK

2 Department of Endocrinology, Imperial College Healthcare NHS Trust, London, UK

3 Department of Surgery, Imperial College Healthcare NHS Trust, London, UK

4 Department of Life Sciences, Brunel University, London, UK
\end{abstract}

complete remission. However, $22.9 \%$ of the patients predicted to have the least chance of remission had either partial or complete remission.

Conclusions In this ethnically diverse cohort, the DiaRem score remains a useful tool to predict diabetes remission in those that have a low DiaRem score (high chance for remission) but was more limited in its predictive power in those with a high DiaRem score (least likely to have remission). Caution must be used in the application of this model in populations other than the US white Caucasian population used to derive the score.

Keywords Diabetes · DiaRem - Diabetes remission · RYGB · Bariatric surgery

\section{Introduction}

The incidence of type 2 diabetes mellitus (T2DM) continues to rise within the UK, driven by the obesity epidemic [1]. Roux-en-Y gastric bypass (RYGB) surgery is currently the most effective treatment for T2DM resulting in long-term remission in a proportion of patients [2-4]. Whilst considered cost-effective and safe, the availability of the operation is unable to meet the demand due to the rapidly rising prevalence of obesity $[5,6]$. Furthermore, although RYGB may result in improvement in obesity comorbidities, not all patients with diabetes undergo remission. In the context of a health service with limited resources, a predictive score for the probability of significant diabetes improvement is required to target surgery only to those most likely to benefit. Current predictive scores 
include the DiaRem [7] and the ABCD scores [8]. The DiaRem score has been validated in three different populations: USA [7, 9], Taiwan [8] and Brazil [10]. However, no external validation has been performed in the UK population. To address this gap, we performed a retrospective study within a tertiary bariatric service in London.

\section{Methods}

We conducted a retrospective review of the records of patients with both obesity and T2DM who had undergone RYGB surgery at Imperial Weight Centre between 2007 and 2014. Preoperative data was collected to calculate the DiaRem score which requires the following: patient's age, preoperative HbA1c, preoperative use of insulin and other diabetic medications [7]. In addition, patient demographics including ethnicity were recorded. Ethnic categorization was based on codes devised by the Office for National Statistics. There are five main categories: 'white', 'mixed', 'Asian or Asian British', 'Black or Black British' and 'other ethnic groups'. In this system, subjects who originate from India, Pakistan and Bangladesh are classified as 'Asian' whilst patients who identify themselves as Chinese are placed in the 'other ethnic group'. Postoperative data was collected at 1-year post-surgery to determine remission of diabetes: fasting glucose, glycated haemoglobin (HbAlc) and diabetic medication.

Remission of diabetes was defined as per the American Diabetes Association (ADA) criteria [11]. Complete remission requires a fasting glucose below $5.6 \mathrm{mmol} / 1$ and an $\mathrm{HbA} 1 \mathrm{c}$ below $6.0 \%$ for 1 year, without the use of any diabetic medication. Partial remission is defined as a fasting glucose between 5.6 and $6.9 \mathrm{mmol} / \mathrm{l}$ and an $\mathrm{HbA} 1 \mathrm{c}$ between 6.0 and $6.5 \%$ for the duration of 1 year, in the absence of any diabetic medication. The patients were therefore analysed for the presence or absence of diabetes remission at least 12 months after surgery.

Patients were divided into five groups by DiaRem score: group $1(0-2)$, group $2(3-7)$, group $3(8-12)$, group 4 (13-17) and group 5 (18-22). In Still et al. [7], a lower DiaRem score predicted a higher chance of diabetes remission, with $88 \%$ of patients in group 1 having partial or complete remission and only $2 \%$ of patients in group 5 having partial or complete remission.

\section{Statistical Analysis}

Data was analysed using GraphPad Prism 6.0 h (GraphPad, San Diego, CA). Paired student's $t$ tests were used to compare pre- and post-surgical variables within our study population, whilst an unpaired $t$ test was used to compare this study population with other validated cohorts. A comparison of medication pre- and post-surgery was performed using a Chi- square test. A Cochran-Armitage test was used to test for significance in the association between trend of diabetes remission and DiaRem score.

\section{Results}

\section{Patient Characteristics}

Two hundred sixty-two patients with T2DM and obesity underwent RYGB surgery at the Imperial Weight Centre between 2007 and 2014. The preoperative demographics are shown in Table 1. There was a higher prevalence of female patients $(59.9 \%)$. The mean age $( \pm \mathrm{SD})$ of the population was $51.0 \pm 9.5$ years and the mean $( \pm \mathrm{SD})$ preoperative weight was $133.4 \pm 23.4 \mathrm{~kg}$. With reference to glycaemic control, the mean $( \pm \mathrm{SD})$ preoperative HbA1c was $8.2 \pm 1.8 \%$. The most common ethnicity was Caucasian (61.1\%) followed by Asian $(10.3 \%)$. At 1-year post-surgery, there were statistically significant reductions in both weight and $\mathrm{HbAlc}$.

\section{DiaRem Scoring and Diabetes Remission}

At 1 year, complete remission was seen in 85 patients $(27.9 \%)$ while partial remission was seen in a further $12(4.6 \%)$. $67.8 \%$ of those with DiaRem score $0-2$ had complete or partial remission, $38.5 \%$ of those with score $3-7,27.9 \%$ of those with score $8-12,9.5 \%$ in those with score $13-17$ and $22.9 \%$ in those with score 18-22 (Table 2).

\section{Discussion}

The DiaRem score is a simple, clinically based scoring system to predict the remission of diabetes following bariatric surgery. However, in our UK-based population, the predictive power of the DiaRem score was reduced (Table 2). Only $68 \%$ of the patients in our cohort with DiaRem score of 0-2 experienced remission (completely or partially) compared to $88 \%$ in the US study [7]. In contrast, at scores of 18-22, $23 \%$ of our patients experienced remission (completely or partially) compared to $2 \%$ in the US study. Validation of the DiaRem score in other populations has revealed similar limitations. Lee et al. studied a Taiwanese population and found also that $>25 \%$ of their patients with the highest DiaRem scores experienced complete remission despite being predicted to have no chance of complete remission according to the Still et al. data [8]. A similar finding in another US cohort by Aminian et al. showed that $20 \%$ of patients with DiaRem scores 18-20 had either partial or complete remission (as opposed to $2 \%$ from Still et al.) [9]. In contrast to this, Sampaio-Neto et al., who studied a small Brazilian population, demonstrated a better predictive power at higher DiaRem scores although there was a disparity 
Table 1 Characteristics of patients who underwent bariatric surgery at the Imperial College Weight Centre 2007 to 2014

\begin{tabular}{|c|c|c|c|}
\hline & Pre-surgery & 1 year post-surgery & $P$ value \\
\hline Age mean (SD) (range) in year & $51(9.5)(23-73)$ & & \\
\hline \multicolumn{4}{|l|}{ Gender no. $(\%)$} \\
\hline Male & $105(40.1)$ & & \\
\hline Female & $157(59.9)$ & & \\
\hline \multicolumn{4}{|l|}{ Ethnicity no. (\%) } \\
\hline Caucasian & $160(61.1)$ & & \\
\hline Asian & $27(10.3)$ & & \\
\hline Black & $14(5.3)$ & & \\
\hline Mixed & $7(2.6)$ & & \\
\hline Other & $54(20.6)$ & & \\
\hline Weight mean (SD) (range) in kg & $133.4(23.4)(83-232)$ & $94.3(20.2)(54.0-181.0)$ & $<0.001$ \\
\hline BMI mean (SD) (range) in $\mathrm{kg} / \mathrm{m}^{2}$ & $45.3(7.1)(33.5-69.2)$ & $32.9(5.9)(29.2-52.9)$ & $<0.001$ \\
\hline $\mathrm{HbA} 1 \mathrm{c}$ mean (SD) (range) in \% & $8.2(1.8)(5.1-16.4)$ & $6.1(1.0)(4.6-10.5)$ & $<0.001$ \\
\hline \multicolumn{4}{|l|}{ Diabetic medication no. $(\%)$} \\
\hline Metformin & $220(84.0)$ & $151(57.6)$ & $<0.0001$ \\
\hline Sulphonylurea & $58(22.1)$ & $2(0.01)$ & $<0.0001$ \\
\hline Other insulin-sensitizing agent & $58(22.1)$ & $7(0.02)$ & $<0.0001$ \\
\hline Insulin & $77(29.4)$ & $48(18.3)$ & $<0.003$ \\
\hline \multicolumn{4}{|c|}{ DiaRem score no. $(\%)$ grouped by score } \\
\hline $0-2$ & $28(10.7)$ & & \\
\hline $3-7$ & $96(36.6)$ & & \\
\hline $8-12$ & $61(23.3)$ & & \\
\hline $13-17$ & $42(16)$ & & \\
\hline $18-22$ & $35(13.4)$ & & \\
\hline
\end{tabular}

at the lowest DiaRem scores of $0-2$ wherein $<50 \%$ experienced complete remission (vs $61 \%$ from Still et al.) [7, 10].

The causes of this disparity between different populations are unclear, and the determination of such causes is beyond the power of a retrospective study. However, it should be noted that in terms of age (mean age 50.5 in Still et al. vs 51.0 years in our study), gender prevalence and BMI (presurgical BMI 48.8 in Still et al. vs $45.3 \mathrm{~kg} / \mathrm{m}^{2}$ in our study), the population studied by Still et al. was similar [7, 8]. The most striking difference is the wider ethnic diversity in our data, which reflects the London-wide population. Ninety- seven percent of patients studied by Still et al. were white Caucasian whilst this was true for only $61.1 \%$ of this cohort. Whilst this observation can only suggest a possible association, it is not inconceivable that ethnic origin may play a role. Previous studies have demonstrated that ethnicity can affect susceptibility to developing T2DM [10, 12] as well as response to diabetes medication, with Asians (who represented $10 \%$ of our study population) doing worse than Caucasians $[7,13]$. Similarly, the difference in DiaRem performance noted in the study of Lee et al. might be explained by the fact that they were studying a Chinese population [8].

Table 2 Comparison of the DiaRem scores from the bariatric surgery population at Imperial Weight Centre $(P<0.0001$ for trends in both CR/PR and PR, Cochran-Armitage test) and from Still et al. [7], Aminian et al. [9], Lee et al. [8] and Sampaio-Neto et al. [10]

\begin{tabular}{|c|c|c|c|c|c|c|c|}
\hline \multirow[b]{2}{*}{ DiaRem score } & \multicolumn{2}{|c|}{ Imperial Weight Centre $(N=262)$} & \multicolumn{2}{|c|}{ Still et al. $(N=690)$} & \multirow{2}{*}{$\begin{array}{l}\text { Aminian et al. } \\
(N=136) \\
\text { CR/PR }(\%)\end{array}$} & \multirow{2}{*}{$\begin{array}{l}\text { Lee et al. } \\
(N=245) \\
\text { CR }(\%)\end{array}$} & \multirow{2}{*}{$\begin{array}{l}\text { Sampaio-Neto } \\
\text { et al. }(N=70) \\
\text { CR }(\%)\end{array}$} \\
\hline & CR/PR no. $(\%)$ & CR no. $(\%)$ & CR/PR (\%) & CR $(\%)$ & & & \\
\hline $0-2$ & $19(67.8)$ & $19(67.8)$ & 88 & 61 & 86 & 100.0 & 45.7 \\
\hline $3-7$ & $37(38.5)$ & $35(38.5)$ & 64 & 32 & 78 & 85.3 & 42.8 \\
\hline $8-12$ & $17(27.9)$ & $12(19.7)$ & 23 & 10 & 30 & 43.5 & 11.4 \\
\hline $13-17$ & $4(9.5)$ & $3(7.1)$ & 11 & 5 & 27 & 38.1 & 0.0 \\
\hline $18-22$ & $8(22.9)$ & $4(11.4)$ & 2 & 0 & 20 & 27.9 & 0.0 \\
\hline
\end{tabular}

Abbreviations: $C R$ complete remission, $P R$ partial remission 
However, there may be alternative causes for the differences observed in our study. The DiaRem score is also affected by prescribing practices. In the UK study population, sulphonylureas and insulin-sensitizing drugs are less commonly used than in the US population (22 vs $32 \%$, respectively, for sulphonylureas; 22 vs $31 \%$ for insulin-sensitizing agents) [7]. Furthermore, based on recent medication surveys, insulin prescription is higher in the UK than in the USA ( 23.3 vs $8.1 \%$, respectively) [14, 15]. These differences, driven by national guidelines, drug licensing and historical practice, affect the DiaRem score and, therefore, may limit the applicability of the score in the UK population as well as other populations with prescribing practices at variance to those in the USA.

This study has several limitations that should be noted. Whilst it represents the largest cohort so far used to validate the DiaRem score, the studied population remains too small to support meaningful subgroup analyses of the different ethnic groups. Furthermore, whilst this represents the first validation of DiaRem within the UK population, the subject data came from a small cohort treated at a single institution and it is unclear whether the results are generalizable to the entire British population.

The DiaRem score provides an easy-to-determine score for predicting diabetes remission to aid decision-making for surgery. Whilst predictive scores are more useful in the context of assessing response within a large population, increasing pressures on both finances and resources mandate the need for a clinical test to guide both surgeons and patients. However, in our population, use of the DiaRem score may falsely deter patients with higher scores from surgery that would benefit a significant proportion. These higher scoring DiaRem patients represent a subpopulation who have generally worse or more long-standing diabetes, and so potentially have the most to gain by undergoing surgery.

A better predictive tool is required to assess patients placed in the higher DiaRem score group. One previous criticism of the DiaRem score is that it does not take into account duration of diabetes [7-9]. Duration of T2DM has previously been demonstrated to be a strong risk factor for remission of diabetes as it may be a surrogate for pancreatic function [16]. This variable was not included as part of the Still et al. multivariate analysis, but determining duration of diabetes can be imprecise due to the absence of a systematic screening process in most countries and the vague symptoms (or even absence of symptoms) associated with this condition. In addition, whilst the DiaRem score is simple to calculate, it fails to take directly into account any of the postulated mechanisms of diabetes remission such as elevated gut hormone [17] or bile acid secretion [18]. Future prospective studies could evaluate the predictive power of measurement of pre-surgical levels of these mediators as well as investigate different ethnic groups in larger numbers. A final limitation of any predictive score that uses diabetes remission as an end point is that it overlooks any significant improvement in both HbA1c and reduction in medication. Whilst diabetes remission was observed in only 85 patients in this cohort, there was a large reduction in the burden of medication (Table 2).

\section{Conclusion}

The DiaRem score, a model used to predict diabetes remission following bariatric surgery, is less successful for the purposes of predicting remission in the patients treated in this single bariatric unit within the UK. Specifically, it is less useful at predicting response in those who have higher DiaRem score. This may reflect differences in ethnic diversity in the studied populations, or differences in prescribing between countries.

\section{Compliance with Ethical Standards}

Conflict of Interest The authors declare that they have no conflict of interest.

Ethical Approval All procedures performed in studies involving human participants were in accordance with the ethical standards of the institutional and/or national research committee and with the 1964 Helsinki declaration and its later amendments or comparable ethical standards.

Informed Consent Informed consent for the surgical procedures undertaken was obtained from all individual participants included in the study.

Open Access This article is distributed under the terms of the Creative Commons Attribution 4.0 International License (http://creativecommons.org/ licenses/by/4.0/), which permits unrestricted use, distribution, and reproduction in any medium, provided you give appropriate credit to the original author(s) and the source, provide a link to the Creative Commons license, and indicate if changes were made.

\section{References}

1. Diabetes UK. Diabetes: diabetes: facts and stats. March 2014.

2. Sjöström L, Peltonen M, Jacobson P, Ahlin S, AnderssonAssarsson J, Anveden $\AA$, et al. Association of bariatric surgery with long-term remission of type 2 diabetes and with microvascular and macrovascular complications. JAMA. 2014;311:2297-304.

3. Mingrone G, Panunzi S, De Gaetano A, Guidone C, Iaconelli A, Nanni G, et al. Bariatric-metabolic surgery versus conventional medical treatment in obese patients with type 2 diabetes: 5 year follow-up of an open-label, single-centre, randomised controlled trial. Lancet. 2015;386:964-73.

4. Schauer PR, Kashyap SR, Wolski K, Brethauer SA, Kirwan JP, Pothier CE, et al. Bariatric surgery versus intensive medical therapy in obese patients with diabetes. N Engl J Med. 2012;366:1567-76.

5. Warren JA, Ewing JA, Hale AL, Blackhurst DW, Bour ES, Scott JD. Cost-effectiveness of bariatric surgery: increasing the economic viability of the most effective treatment for type II diabetes mellitus. Am Surg. 2015;81:807-11. 
6. Buchwald H, Avidor Y, Braunwald E, Jensen MD. Bariatric surgery: a systematic review and meta-analysis. JAMA. 2004;292:1727-37.

7. Still CD, Wood GC, Benotti P, Petrick AT, Gabrielsen J, Strodel WE, et al. Preoperative prediction of type 2 diabetes remission after Roux-en-Y gastric bypass surgery: a retrospective cohort study. Lancet Diabetes Endocrinol. 2014;2:38-45.

8. Lee W-J, Chong K, Chen S-C, Zachariah J, Ser K-H, Lee Y-C, et al. Preoperative prediction of type 2 diabetes remission after gastric bypass surgery: a comparison of DiaRem scores and ABCD scores. Obes Surg. 2016.

9. Aminian A, Brethauer SA, Kashyap SR, Kirwan JP, Schauer PR. DiaRem score: external validation. Lancet Diabetes Endocrinol. 2014;2:12-3.

10. Sampaio-Neto J, Nassif LS, Branco-Filho AJ, Bolfarini LA, Loro LS, de Souza MP, et al. External validation of the diarem score as remission predictor of diabetes mellitus type 2 in obese patients undergoing roux-en-y gastric bypass. Arq Bras Cir Dig. 2015;28(Suppl 1):19-22.

11. Buse JB, Caprio S, Cefalu WT, Ceriello A, Del Prato S, Inzucchi SE, et al. How do we define cure of diabetes? Diabetes Care. 2009;32:2133-5.

12. Kodama K, Tojjar D, Yamada S, Toda K, Patel CJ, Butte AJ. Ethnic differences in the relationship between insulin sensitivity and insulin response: a systematic review and meta-analysis. Diabetes Care. 2013;36:1789-96.
13. James GD, Baker P, Badrick E, Mathur R, Hull S, Robson J. Type 2 diabetes: a cohort study of treatment, ethnic and social group influences on glycated haemoglobin. BMJ Open. 2012;2.

14. Sharma M, Nazareth I, Petersen I. Trends in incidence, prevalence and prescribing in type 2 diabetes mellitus between 2000 and 2013 in primary care: a retrospective cohort study. BMJ Open. 2016;6: e010210.

15. Pantalone KM, Hobbs TM, Wells BJ, Kong SX, Kattan MW, Bouchard J, et al. Changes in characteristics and treatment patterns of patients with newly diagnosed type 2 diabetes in a large United States integrated health system between 2008 and 2013. Clin Med Insights Endocrinol Diabetes. 2016;9:23-30.

16. Panunzi S, Carlsson L, De Gaetano A, Peltonen M, Rice T, Sjöström L, et al. Determinants of diabetes remission and glycemic control after bariatric surgery. Diabetes Care. 2016;39: 166-74.

17. le Roux CW, Welbourn R, Werling M, Osborne A, Kokkinos A, Laurenius A, et al. Gut hormones as mediators of appetite and weight loss after Roux-en-Y gastric bypass. Ann Surg. 2007;246: $780-5$.

18. Yu H, Ni Y, Bao Y, Zhang P, Zhao A, Chen T, et al. Chenodeoxycholic acid as a potential prognostic marker for Roux-en-Y gastric bypass in Chinese obese patients. Journal of Clinical Endocrinology \& Metabolism. 2015;100:4222-30. 